\title{
PREFACE: TECHNICAL COMMISSION III
}

\author{
Jie Jiang ${ }^{1}$, Ahmed Shaker ${ }^{2}$, Hongping Zhang ${ }^{3}$ \\ ${ }^{1}$ President of TC III, Beijing University of Civil Engineering and Architecture, China -jiangjie@bucea.edu.cn \\ ${ }^{2}$ Vice President of TC III, Ryerson University, Canada - ahmed.shaker@ ryerson.ca \\ ${ }^{3}$ Secretary, National Geomatics Center of China, China - zhanghongping@ngcc.cn
}

The work of ISPRS Technical Commission III is devoted to remote sensing. For the XXIVth ISPRS CONGRESS 2021 Edition (Digital), Technical Commission III received total 201 submissions, including 72 full papers and 138 abstracts. Among these submissions 38 are accepted as peer-reviewed contributions for publication in the ISPRS Annals, 118 were accepted for publication in the ISPRS Archives.

These papers are dedicated mostly to topics of the 10 TC III working groups and 4 inter-commission working groups as follows - WG III/1: Thematic Information Extraction; WG III/2: Microwave Remote Sensing; WG III/3: SAR-based Surface Generation and Deformation Monitoring; WG III/4: Hyperspectral Image Processing; WG III/5: Information Extraction from LiDAR Intensity Data; WG III/6: Remote Sensing Data Fusion; WG III/7: Landuse and Landcover Change Detection; WG III/8: Remote Sensing of Atmospheric Environment; WG III/9: Cryosphere and Hydrosphere; WG III/10: Agriculture and Natural Ecosystems Modelling and Monitoring; ICWG III/II: Planetary Remote Sensing and Mapping; ICWG III/Iva: Disaster Assessment, Monitoring and Management; ICWG III/IVb: Remote Sensing Data Quality; ICWG III/IVc: Environment and Health. The papers and abstracts were evaluated by the experts in the field and Working Group Chairs according to content, significance, originality, relevance, and clearness of presentation.

We would like to thank the authors for their contributions, the reviewers for their reviewing, the working group officers for their efforts on calling for papers, and the organizers of the Congress for publishing this volume.

\section{ISPRS TC III officers:}

Saygin Abdikan, Bulent Ecevit University, Turkey; Hussein M. Abdulmuttalib, Dubai Municipality, UAE; Orhan Altan, Istanbul Technical University, Turkey; Vittorio Barale, DG Joint Research Centre, Italy; Luigi Barazzetti, Politecnico Milano, Italy; Árpád Barsi, Budapest University of Technology and Economics, Hungary; Thomas Blaschke, University of Salzburg, Austria; Anna Brook, University of Haifa, Israel; Madhu Chandra, Chemnitz University of Technology, Germany; Mattia Crespi, University of Rome "La Sapienza", Italy; Michele Crosetto, Centre Tecnolòic de Telecomunicacions de Catalunya, Spain; Beata Csatho, University at Buffalo, SUNY, USA; Kaichang Di, Institute of Remote Sensing and Digital Earth, China; Fazlay S. Faruque, University of Mississippi Medical Ctr, USA; Eija Honkavaara, National Land Survey of Finland, Finland; Baoxin Hu, York University, Canada; Guoman Huang, Chinese Academy of Surveying and Mapping, China; Muralikrishna V. Iyyanki, Defence Research and Development Organization, India; Junichi Susaki, Kyoto University, Japan; Irina Karachevtseva, Moscow University of Geodesy and Cartography, Russia; Konstantinos Karantzalos, National Technical University of Athens, Greece; Ana Paula Baungarten Kersting, Teledyne Optech, Canada; Pradeep Khatri, Tohoku University, Japan; Brigitte Leblon, University of New Brunswick, Canada; Rongxing (Ron) Li, Tongji University, China; Zhenhong Li, Newcastle University, UK; Xianlian Liang, National Land Survey of Finland, Finland; Xiangguo Lin, Chinese Academy of Surveying and Mapping, China; Diego Loyola, German Aerospace Center, Germany; John B. Malone, Louisiana State University, USA; Maria Teresa Melis, University of Cagliari, Italy; Md. Surabuddin Mondal, Wollega University, Ethiopia; Jürgen Oberst, German Aerospace Center, Germany; Batuhan Osmanoglu, NASA Goddard Space Flight Center, USA; Jaime Hernández, Palma Universidad de Chile, Chile; Ammatzia Peled, University of Haifa, Israel; Francesco Pirotti, University of Padova, Italy; Ilkka Pölönen,, University of Jyväskylä, Finland; Gang Qiao, Tongji University, China; Kai Qin, China University of Mining \& Technology, China; Shibendu Shankar Ray Mahalanobis, National Crop Forecast Centre, India; Bahram Salehi, State University of New York, USA; Marco Scaioni, Politecnico Milano, Italy; Uwe Soergel, University Stuttgart, Germany; Tullio Joseph Tanzi, Telecom ParisTech., France; Yves M. Tourre, Anewworld and CNES, France; Serkan Ural, Hacettepe University, Turkey; Jana Viessmann, Chemnitz University of Technology, Germany; Bo Wu, The Hong Kong Polytechnic University, HK China, Lixin Wu, Central South University, China; Wei Yao, The Hong Kong Polytechnic University, HK China; Mitsunori Yoshimura, The University of Tokyo, Japan; Yongnian Zeng, Central South University, China; Jixian Zhang, National Quality Inspection and Testing Center for Surveying and Mapping Products, China; Guoqing Zhou, Guilin University of Technology, China. 